\title{
Deconstructing To Construct: Evaluating Speaking Tasks on a Language Proficiency Course to help develop an appropriate Test Design for Assessing Speaking
}

\author{
Tulika Prasad \\ (Department of English, Satyawati College (E), University of Delhi, India)
}

\begin{abstract}
Speaking is an important skill that needs to be developed in students to fulfill their academic and professional needs. This paper examines the different kinds of speaking tasks, teachers use to teach speaking skills to students in the English language proficiency course (ELPC) at University of Delhi, Delhi, with the aim of developing appropriate test items for speaking test and also develop an assessment scale to assess the oral competence of learners in speaking the language in a multilingual context. For this purpose, a questionnaire was prepared to elicit responses from the teachers on the issue at hand. The responses provided details about the kind of tasks used to teach speaking, the sub skills of speaking taught through these tasks, and the need to develop more tasks to add variety to the existing tasks. They also shed light on which tasks did not work well and needed to be discarded, and the type of tasks preferred by most students. This feedback from teachers will serve to facilitate the designing a valid test to assess speaking.
\end{abstract}

Keywords: oral skills, tasks, multilingual, assessment, proficiency, test

\section{INTRODUCTION}

This paper is based on research undertaken to evaluate and analyze the kind of teaching materials that are being used to teach oral skills to students of Delhi University. The information gathered will help to develop appropriate test items in speaking and also an assessment scale for speaking in a multilingual context.

The university runs a non-credit English Language Proficiency course (ELPC) at three levels namely Basic, Intermediate and Advanced for students at the University. The basic focus of the course is to help students become proficient in all the four skills of English i.e. listening, reading, speaking and writing. Some of the specific objectives of the course are to enable the students to:

- Understand and respond to spoken language.

- Learn how to speak fluently and use appropriate expressions.

- Read and comprehend different kinds of texts for different purposes.

- Write coherently and effectively in formal and informal contexts.

Most of the students who enroll on this course belong to the socially disadvantaged sections of society. For these students who have not been afforded an opportunity to learn English but nevertheless would like to do so join the course to improve their English language skills.

\section{RATIONALE FOR THE STUDY}

The study is undertaken to examine the issue of English Language testing and assessment and more specifically testing and assessment of speaking skills in a multilingual context. This research was undertaken in order to understand the needs of the students in improving their language skills, what is it that the students were able to learn with the help of the materials used by the teacher and gaps if any in the materials used by the teachers. Specifically, the analysis of this data would help to develop valid test items in speaking and facilitate the construction of a valid and reliable assessment scale in speaking in a multilingual milieu, though this is not the only parameter on which it can be developed.

This would also help in improving the oral competence of students, and enable them to have a clear picture of their level of competence in the spoken language. Moreover, such an assessment would encourage them to improve their spoken skills so that they are able to use the language in real-life situations which they may encounter in study, social or job related activities.

According to Luoma (2004, p.1) 'Speaking skills are an important part of the language curriculum in language teaching and this makes them an important object of assessment as well.' [1] Assessing speaking is challenging, however, because there are so many factors that influence our impression of how well someone can speak a language, and because we expect test scores to be accurate, just and appropriate for our purpose. 


\section{METHODOLOGY}

Since the aim was to evaluate the tasks/ materials used by teachers to impart English speaking skills to students, to collect primary data, a questionnaire was developed to obtain feedback from the teachers who taught on the ELPC programme. Questionnaires are a quick and simple way of obtaining broad and rich information.

\section{DEVELOPING A QUESTIONNAIRE}

Developing a questionnaire is difficult and confusing and as Oppenheim (1966: vii), in the preface to his book Questionnaire and Attitude Measurement, wrote that 'the world is full of well-meaning people who believe that anyone who can write plain English and has a modicum of common sense can produce a good questionnaire'. [2] On the contrary this is not sufficient. Care has to be taken in selecting question type, in question writing, in the design, piloting, distribution and return of questionnaires. The questions posed in a questionnaire should provoke the respondent to engage with it in a manner which will help the researcher to elicit appropriate responses, leading to valid results which are meaningful both for the researcher and the practitioner.

According to Fowler (2002), there are four cases of reduced accuracy in a questionnaire:

- Respondents fail to understand the question.

- Respondents do not know the answer.

- Respondents do not remember the answer at that point of time though they were aware of it at some point earlier.

- Respondents are not willing to share the answer though they know it. [3]

Some don'ts while framing a good questionnaire:

- Avoid negative and double negative phrases in the questionnaire.

- Avoid asking two questions in one question.

- Minimize bias while phrasing questions.

- Avoid using difficult words/ phrases while framing questions.

- Avoid leading or presumptuous questions.

- Avoid hypothetical questions.

- Avoid offensive questions and questions covering sensitive issues. Youngman (1987) gives a list of seven question types which can be included in a good questionnaire. According to Youngman the more structured a question the easier its analysis. [4]

- Verbal or open questions: Responses to these questions could be one word/ phrase or an extended comment. The information received can be useful but difficult to analyze.

- List : A list of items given and the respondent can select one or more than one item from the list.

- Category: A set of categories given and respondent can fit only into one of it.

- Ranking: The respondent is expected to place something in rank order.

- Scale: A scaling device provided to respond to, but they require careful handling.

- Quantity : The response could be a number.

- Grid: A table is provided to record answers to two or more questions at the same time. Some dos while framing a good questionnaire:

- Decide on the appropriate question type depending on the objectives of the study.

- Check the wording of each question. Language should be simple, clear and precise.

- Sequence the questions in the order you think is appropriate. Ask sensitive questions at the end.

- Instructions to respondents should be unambiguous. Have a different font for the instructions to get the attention of the respondents.

- Look critically at the questions /questionnaire to avoid ambiguity.

- Layout of the questionnaire should be neat and encourage the respondent to read and respond to the questions. An untidy document may put off the respondent.

Keeping all these issues in mind an appropriate questionnaire was developed to serve the objectives of the study. The initial drafts of the questionnaire had questions which were verbose and lacked clarity and it would become a challenge for the respondent to decode the meaning and then respond to it. Three drafts of the questionnaire were made before developing the final draft of the questionnaire which was appropriate and would facilitate the objectives of the study. The majority of the questions were open ended.

\section{Given below is a preface to the questionnaire and the set of questions:}

I would like you to give your critical, honest and detailed comments/observations on the Questionnaire. The questionnaire will focus on the tasks available in the materials to develop speaking skills. What I am looking for is your detailed comment on the variety of tasks that we have, to develop proficiency in speaking. The reason for doing this is to get valid feedback about the tasks so that the suggestions and critique can help me 
to create valid and reliable test items to assess speaking skills of students. The Questionnaire may miss out on some issues which you think are important. Please include those points when you are responding to the questions.

- Do you think that the ELPC materials have sufficient tasks for developing speaking skills?

- Is there a variety of tasks to help develop speaking skill? (Please give examples to substantiate your statement.)

- Which are the tasks which work very well in class and why?

- What are the various aspects of the spoken language which are developed through these tasks?

- Please give suggestions to improve and develop more speaking tasks and to delete/remove tasks which you think do not help in improving speaking.

Sample size: Since there was limited time in which one had to go through the whole process of preparing the questionnaire, selecting the respondents and then analyzing the responses, it was decided to have a sample size of six teachers(all of whom had taught at ELPC) to respond to my questionnaire. This choice was not a random decision, but had a rationale. The teachers ranged in the age group of 30 to 65 years. Care was taken to ensure variety not only in terms of teaching experience at colleges, but also in terms of what they taught in the college. A couple of them were literature teachers who had never taught language earlier, one was also a research scholar at Delhi University, one of them was a B. El. Ed. teacher in a college and two teachers had taught only language in their college. There was variety also in terms of the kind of students they had taught at ELPC. Some of the students were from the School of Open Learning who never had an opportunity to attend regular college; others were students at the postgraduate level belonging to different disciplines like Geography, Computer Science, Urdu, Punjabi, and Buddhist Studies. Some of the students were M.Phil and Ph. D. students and yet others who were either pursuing honors in a subject or doing B. El. Ed. Some of the teachers had also taught foreign students (Vietnamese, Sri Lankan, Bangladeshi, French, Kazakhstani, Iranians, Afghanistanis etc.), who had varying levels of proficiency. As mentioned earlier we have three levels of proficiency at ELPC namely Basic, Intermediate and Advanced and all these teachers had taught at least two levels. Some of them had taught ELPC for three years and others for close to five years. The decision to have this kind of a range in the sample was to make the responses more valid and also get a varied perspective on the questionnaire. This would help to make the study more valid, reliable and useful both for language learners and teachers.

The questionnaire was mailed to the teachers but only after one had engaged in a conversation with them about the objective and the rationale of the study. None of the teachers showed any reluctance to respond to the questionnaire nor asked reasons about why they had been chosen. This kind of willingness confirmed that they would respond in a serious and objective manner and it also reflected their commitment to ELPC. A short note was written at the beginning of the questionnaire (refer to the questionnaire) to inform them as to what was expected of them while responding to the questionnaire.

Although it is not an accepted practice to give the agenda of the questionnaire to the respondents but nevertheless it was done. One thought that it would only add value to the document and help in eliciting honest and meaningful responses. The respondents were requested to ensure that all the questions had been answered and the questionnaire sent back in a week's time. A couple of phone calls and reminders ensured that the document was sent back within a week.

\section{PROCESSING AND ANALYZING THE DATA}

In order to get a holistic picture and for easy reference, the responses of the teachers on each question was collated. Unless there was a disparate response or voice which was then put in quotes, the common responses were put down together. This would give us a picture of the recurrent themes in the questionnaire. The next step was to reduce this mass of data to a form suitable for analysis. This process is called data reduction but the questionnaire did not lend itself to this to a great extent because most of the questions were open-ended. Yet an attempt was made to summarize some of the responses and make clusters of similar responses. Prior to this, one engaged in editing the questionnaire in terms of whether all the questions had been answered by all the respondents, answered accurately as far as possible and also that all the respondents had interpreted the instructions and questions uniformly.

Given below are the questions and responses of teachers.

Q. Do you think that the ELPC materials have sufficient tasks for developing speaking skills?

- Yes (all respondents)

Q. Is there a variety of tasks to help develop speaking skill? (Please give examples to substantiate your statement.)

- Yes, there are a variety of tasks to help develop speaking skills.

- There is more variety in speaking tasks than in other skills, which is according to the need expressed by these students themselves. 
- From the very first session, the required emphasis on speaking is present. The tasks range from making introductions, ice- breakers, communication in various simulated social situations, role-plays, groupdiscussions, debates, preparing chat-shows, expressing opinions, preparing skits, formal presentations, appearing in interviews, conducting games and quizzes etc. This ensures that learners are exposed to different situations and milieu and are not intimidated by any situation they arrive at. It also builds their confidence and helps remove hesitation which results in better communication. Students feel they get a voice through these speaking tasks.

Q. Which are the tasks which work very well in class and why?

- Students were found to respond well on tasks that involved talking about their personal life, family, friend or presenting their viewpoints on an issue/topic.

- Role plays usually work well with these students. One can see them making an effort to use language to convey meaning. Role plays are successful also because here the students' focus is on the use of appropriate language to articulate their point and is largely unconscious. This is actual use language for communicative purpose. In role play, students learn to confront situations in real life, and the required responses. Also, these sessions bring a lively atmosphere to the class, so that learning becomes enjoyable.

- Preparing and writing skits work very well as these activities are in groups so learners feel more at ease. They are also mostly informal so the fear and hesitation that they have regarding making mistakes is considerably lowered, resulting in better performance. The learning is also enhanced as these activities help them interact and build healthy relationships with each other.

- Group discussions, serve several useful purposes. They are a practice for real life situations where in future, the skill of being able to state and defend a point of view, an opinion is vital. Additionally, they are learning to shape their ideas on relevant issues.

- Interviews also work very well as our students are constantly appearing for the same regarding summer jobs, part time jobs, internships and full-time jobs.

- Finally, by inviting the students to describe or react to a given picture, they get the freedom to speak as they wish to, giving their imagination free play.

Q. What are the various aspects of the spoken language which are developed through these tasks?

- Making them confident speakers

- Improvement in fluency though to a limited extent

- Improvement in expression

- Organizing ideas into speech

- Giving them a sense of audience (personal and external)

- Using language to share feelings and ideas

- Speaking for various purposes like speaking for describing, speaking for asking directions, speaking for requesting, speaking to narrate, speaking to explain, speaking to inform or inquire, speaking for persuading

- Helped the students focus on meaning rather than form.

- Confidence building in making presentations

- Overcoming shyness in conversing

- Improvement in pronunciation

Q. Please give suggestions to improve and develop more speaking tasks and to delete/remove tasks which you

think do not help in improving speaking.

- Topics should also include more topical themes which can them help them relate better to the materials.

- Stage performances could be incorporated as it goes a long way in improving their confidence and selfesteem.

- Some project work followed by group/individual presentation could also be part of the materials.

- What would help immensely, if some way could be found of giving them time and scope for repetition and practice.

- It would be ideal if some technology could be used. May be, a passage, which they have, and a recording of it by a native speaker of the language.

- On the elementary but essential side, more exercise in using interrogative and negative forms could be useful.

- There can be more tasks for group discussion.

- More ideas for role play

- Short video clips for commentary/pair discussion.

- It is important for us to have a clear understanding of objectives at the beginning of each lesson.

- Some of the tasks do not match the nature of objectives that have been set for ELPC. The mismatch ought to be removed. 
- The tasks can become very literal if the teacher is not aware of the objectives so a conscious explanation of the task and its individual objectives is essential.

- The tasks ought to be constantly revised as some students repeat the program and therefore the same tasks become very boring.

The next stage was the analysis and interpretation of the data procured. The responses to the questionnaire gave one a fair idea of the kind of tasks used by the teachers on this course. It also informed the different kinds of tasks students were able to negotiate with comfortably and tasks which students enjoyed in the classroom. The information from the questionnaire also reflected the different aspects of the spoken language which the students had acquired through the tasks.

The objective to develop valid test items based on these responses is served to some extent. The various tasks which the students engaged with to improve their speaking proficiency will help to develop similar test items. The familiarity of students with these tasks in the classroom will also help them to perform better with similar tasks during the test. The emphasis on group work being appreciated by students as reflected in the responses inclines one to make test items which are group-oriented. Though this makes construction and assessment of these kinds of test items difficult one will still attempt to make them.

The questionnaire also reflects the various aspects of the spoken language which students have learnt through the variety of tasks. This will give an opportunity to develop a variety of test items which can test these different aspects of the spoken language. The questionnaire suggests a lot of tasks which need to be included in the tasks to teach students speaking in the classroom. There is a possibility that these task types could teach speaking in a more effective manner and similar test items would reflect a measure of their speaking competence in a more accurate manner.

\section{CONCLUSION}

This study is limited in some ways. Since the sample size was very small, there is a possibility that some important aspects of the different kinds of tasks to teach speaking may have been missed out on. The responses to the questions were based on the experience and interaction of only six teachers who have taught 300 to 400 students only, whereas more than 6000 students have taken the course in a span of five years. The data obtained through the questionnaire may not hold good in all respects because it is representative of a very small section of ELPC students. The first question of the questionnaire did not yield any data apart from reaffirming the question. These kinds of questions which do not support or facilitate the study should be avoided. The responses in the questionnaire does not help in the construction of a good assessment scale, though it does give one some pointers to be included in the scale. These pointers were culled from the fourth question which lists the various aspects of the spoken language which the students acquire through the tasks on teaching speaking skills. On the whole using a Questionnaire as a tool to do a study does facilitate the research, but it is very important to develop a robust Questionnaire to support the research.

\section{REFERENCES}

[1] S.Luoma, Assessing Speaking. (Cambridge, Cambridge University Press, 2004).

[2] N.Oppenheim, Questionnaire Design and Attitude Measurement(London, Heineman, 1966)

[3] F. J.Fowler, Survey research methods (Thousand Oaks, CA, Sage Publications 2002).

[4] M. B. Youngman, Designing and Analysing Questionnaires (Rediguide 12, Nottingham, School of Education, University of

Nottingham, 1987) 